\title{
Phase equilibria and electrical properties of pyrochlore and zirconolite phases in the Bi2O3-ZnO-Ta2O5 system.
}

\begin{abstract}
The complete subsolidus phase diagram of the system $\mathrm{Bi} 2 \mathrm{O} 3-\mathrm{ZnO}-\mathrm{Ta} 2 \mathrm{O} 5$, including cubic pyrochlore and monoclinic zirconolite phases, has been determined at $950-1050{ }^{\circ} \mathrm{C}$. Through systematic heat treatment and X-ray diffraction of over 100 compositions, the layout of compatibility triangles (both 2-phase and 3-phase) and single phase solid solution areas has been determined. Pyrochlore and zirconolite phases have ideal nominal compositions $\mathrm{Bi1}$.5Zn1.0Ta1.5O7 and $\mathrm{Bi} 2(\mathrm{Zn} 1 / 3 \mathrm{Ta} 2 / 3) 2 \mathrm{O} 7$ respectively, but both form solid solution areas. The sintering condition of pyrochlore pellets has been optimised to obtain high density ceramics with minimal weight loss: optimised condition is $1100{ }^{\circ} \mathrm{C}$ for pellets covered with sacrificial powder. Permittivity, $\varepsilon^{\prime}$ dielectric loss and temperature coefficient of capacitance, TCC, of single phase materials were measured using impedance spectroscopy; $\varepsilon^{\prime}$ and TCC show little variation with composition but the losses are higher for $\mathrm{Zn}$-deficient compositions.
\end{abstract}

Keyword: Powder solid-state reaction; Sintering; X-ray methods; Electrical properties. 